\title{
Adoption of Improved Bread Wheat Varieties on Small- Scale Farmers: The Case of Boji Gebisa Ambo District, Oromia Regional State, Ethiopia
}

\author{
Mideksa Bekele, Tadele Shiberu* \\ Department of Plant Sciences, College of Agriculture and Veterinary Sciences, Ambo University, Ethiopia \\ *Corresponding author: tshiberu@yahoo.com
}

Received March 25, 2014; Revised April 12, 2014; Accepted July 10, 2014

\begin{abstract}
Wheat (Triticum aestivum L.) is one of the most crop grown in the highlands of and thi region is regarded as the second largest wheat production in sub-Saharan Africa and its contribution to the human diet put it Cleary in the first rank of plants that feed the world. This study was conducted in boji Gebisa, Ambo District, West Shoa, Ethiopia. The study was indicated to assess the adoption of improved bread wheat varieties for small scale farmers, to know the rate of adoption and to identify the major constraints associated with adoption of improved bread wheat varieties. The data were collected from both primary and secondary data sources. So that, the primary data was collected from sample respondents through personal interviews, structured questionnaires and personal observations. Also the secondary data sources were used for the published materials, offices document and annual reports. In this study, systematic random sampling techniques was followed to select 40 respondents. The data were analyzed using descriptive statistics, percentage, graph and tabulation form which employed to analysis and interpret the collected data. The study showed about $67.5 \%$ of the respondents were adopters and $32.5 \%$ non- adopters. The adoption rate of improved bread wheat varieties were increased from $10 \%$ in 2008 to $67.5 \%$ in 2013. So, the rate of adoption was increased dramatically since the agricultural extension services were strongly implemented. Millennium and HAR1685 (Kubsa) were the most popular improved bread wheat varieties grown by the most farmers and followed by Digelu, Danda'a and Kakeba, respectively. The main reason why the non-adopters did not grow improved bread wheat varieties due to financial constraints and high-cost of improved seeds. For the strength of wheat production system, the existences of strong farmers-extension-research linkage among actors within the system has a vital importance in a way that to transfer skill, knowledge and provision of improved bread wheat varieties in efficient and effective manner is mandatory.
\end{abstract}

Keywords: adoption, bread wheat, improved varieties and farmers

Cite This Article: Mideksa Bekele, and Tadele Shiberu, “Adoption of Improved Bread Wheat Varieties on Small-Scale Farmers: The Case of Boji Gebisa Ambo District, Oromia Regional State, Ethiopia.” American Journal of Food Science and Technology, vol. 2, no. 3 (2014): 103-108. doi: 10.12691/ajfst-2-3-5.

\section{Introduction}

Bread wheat (Triticum aestivum L.) and durum wheat (T. Turgidum spp, durum L.) are the two major species of wheat cultivated in Ethiopia. T. aestivum is one of the important grain crops produced worldwide. FAO (2005) reported that about 620 million metric ton of wheat was produced from 217 million hectares in the year 2005/06 with an average yield of 2.85 metric tons per hectare.

Wheat is used for the manufacture of flour for different purposes such as bread, biscuits and pasta products such as macaroni, spaghetti and noodle are some of the industrial products. Wheat is known to be a major source of energy and protein. Traditionally, Wheat is used for making "dabo", “dabokolo", "gonfo", "kinche” and other types of food (Hanson et.al, 1982). Wheat is not only for making bread, biscuit and pastry products, but also for the production of starch and gluten.
In sub-Saharan Africa, Ethiopia ranks second to South Africa in terms of total wheat area and production. In Ethiopia, wheat ranks fourth after Teff, Maize and Sorghum in area coverage and third in total production (CSA, 2012).The average per capital consumption of wheat in Ethiopia estimated to be $39 \mathrm{~kg} /$ year during 199497 and 331,000 tons of wheat imported to meet the national wheat requirements during 1995-97 (CIMMYT, 2000).

Ethiopia is the largest wheat producer in Sub-Saharan Africa. The total area under both durum and bread wheat was about $14.6 \%$ of total cereal area in 1998/99 statistical data and wheat literature reveal that Ethiopia produce surplus wheat and also exported wheat during the 1960, and early 1970 (EARO, 2000). In terms of area and total production on a national basis, wheat rank fifth following tef, maize and sorghum (CSA, 1999). It is largely grown in the highlands of the country and constitutes roughly $10 \%$ of the annual cereal production and plays as 
appreciable role in supplying the population with carbohydrates, protein and minerals (Schulthess et al., 1997). The crops is grown at an altitude ranging from 1500 to 3000 meter above sea level (masl), between $6-16^{\circ} \mathrm{N}$ latitude and $35-42^{\circ} \mathrm{E}$ longitude. The most suitable agroecological zones, however, fall between 1900 and 2700 masl (Bekele et. al, 2000).

The productivity of wheat in Ethiopia is low as compared to other wheat producing countries of the world. Because the use of traditional production systems, the influence of biotic factors and abiotic factors, the un availability of production inputs and sub optimal use of the recommended packages. Since the inception of bread wheat research in Ethiopia, fairly high number of improved bread and durum wheat cultivars have been released to farmers most of which were developed from introduced germplasm, mainly CIMMYT and Mexico (CIMMYT, 2000).

In the study area, majority of the farmers have been using tradition way of agricultural practice and using old cultivar that has low production and productivity as well as susceptible to disease. There are few farmers who adopt some of the improved bread wheat varieties. This indicates that there are different factors directly or indirectly influencing the adoption of improved bread wheat varieties that believed to decrease the production and productivity of the small scale farmers. The reasons why most of the farmers failed to adopt new improved bread wheat varieties are not analyzed so far in the study area. Therefore, this study focused on the identification and analysis of major constraints associated with the adoption of improved bread wheat varieties.

\section{Materials and Methods}

\subsection{Description of the Study Area}

Ambo district is located in West Shoa Zone of Oromia Regional State of Ethiopia, at $115 \mathrm{~km}$ away from Addis Ababa. The district has 34 peasant association (PA) and one town in the district. In this case Boji Gebisa was one of the PA where the study was conducted that lies the altitude of 2195 masl which is Weyna Dega Zone. The amount of rainfall ranges between $800-1115 \mathrm{~mm}$ and characterized relatively by warm temperature ranging between $11.7^{\circ} \mathrm{C}$ and to $25.4^{\circ} \mathrm{C}$ and vertisol and clay loam soil type. The area coverage of Boji Gebisa was 1319 hectare of which is 1198 hectare used for crop production, 59 hectare used for grazing land, 12 hectare is natural forest and shrubs, 42 hectare occupied by settlement and 8 hectare used for other purpose. The peasant association had 521 house hold farmers (346 male and 175 female) headed house hold farmer. The population size of Boji Gebisa was 2064 of which women account for $51 \%$ and male account for $49 \%$ of the population.

\subsection{Methods of Data Collection}

Based on the nature, scope, availability of budget and time, the data used for this research will be both primary and secondary data source. The primary data sources are (1) personal interview with agricultural profession and household farmers through direct communication with respondents (2) personal observation (3) personal visiting and (4) questionnaire will be used for primary data collection. The interview schedule will be consists different type of questionnaires related to the research topic and relevant variables together with the needed information. Thus structural interview schedule will be developed and used in order to allow the respondents to freely express their opinion on issues related to the research topic. After formulating the interview schedule, necessarily editing will be done for its observed consistency and logical sequence with farmer of reference of the respondents. Then it will be subjected to a pilot study on sample respondents with a medium and adequate sample size. Finally, the secondary data used for this research are office document and annual reports.

\subsection{Sampling Technique and Sample Size}

For this research systematic random sampling will be used to identify the sample unit as well as to collect reliable, accurate and adequate data. The sampling techniques will be followed to select 40 respondents from 521 household farmers in the peasant association. So that, $\mathrm{N}=521, \mathrm{n}=40, \mathrm{~N} / \mathrm{n}=13$ where $\mathrm{N}$ is the total household farmers in the PA, $\mathrm{n}$ is the representative sample that select from an individual household farmers of 521 members of the peasant association with an interval of 13 house hold farmers. Also female leaded house hold in the selected peasant association will be included in the sample unit according to their participation on crop production.

\subsection{Data Analysis}

The data was analyzed from both primary and secondary data source using different quantitative procedures and methods. The quantitative data will be analyzed using descriptive statistics, percentage, numbers, graph and tabulation form of descriptive statistics has been employed.

\section{Result and Discussion}

\subsection{Demographic Characteristics}

\subsubsection{Sex and Age Distribution of the Sample Respondents}

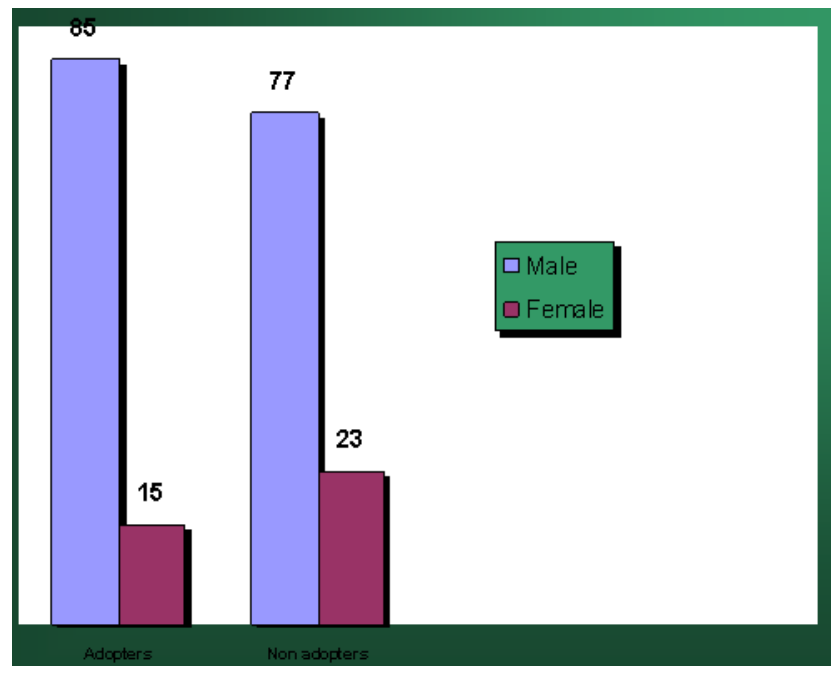

Graph 1. Sex Distribution of the Sample Respondents 
The demographic characteristics of the adopters and non-adopters of improved bread wheat varieties were as follows: about $67.5 \%$ of the respondents were adopters and $32.5 \%$ were non- adopters. From these $85 \%$ and 15\% of the adopters were male and female, respectively. Whereas $77 \%$ and $23 \%$ of the non-adopters were male and female, respectively. In terms age $29.6 \%$ of the adopters and $23 \%$ of non-adopters were between 18-30 years old followed by $59.3 \%$ of adopter and $30.8 \%$ of non-adopters were between $31-50$ years old as well as $11.1 \%$ of adopters and $46.2 \%$ of non-adopters were 51 years old and above. The data showed that most of the adopters were younger than non-adopters and young house hold farmers were more adopter than old house old farmer.

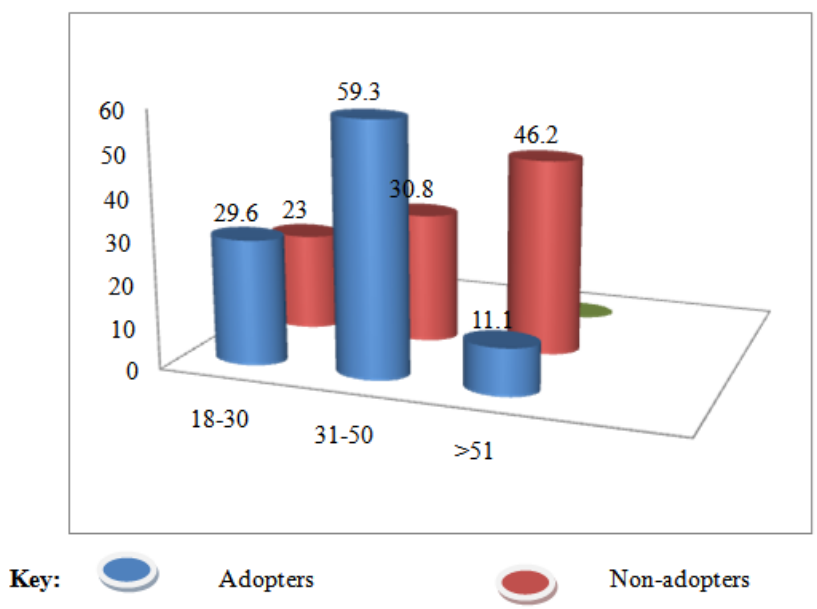

Graph 2. Age of the Sample Respondents

\subsubsection{Marital Status and Religions of the Respondents}

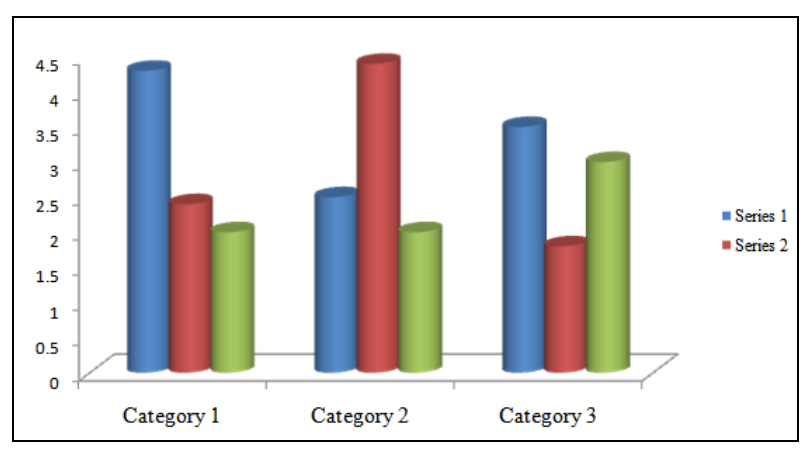

Graph 3. Marital status of respondents

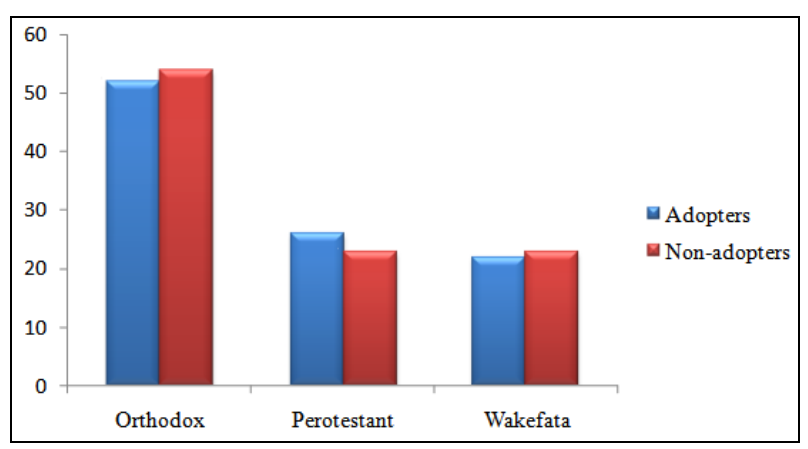

Graph 4. Religion Status of the Respondents

In the sample respondents the percentage of adopters that married, widowed and divorced were $81.5 \%$, 7.4\% and $11.1 \%$ respectively. Whereas the percentage of non- adopters that were married, widowed and divorced were $76.9 \%, 7.7 \%$ and $15.4 \%$, respectively.

Most of the adopters 52\% Orthodox, 26\% Protestant and 22\% indigenous Oromo religion 'Wakefata' believers as well as 54\%, 23\% and 23\% of Orthodox, Protestant and 'Wakefata' believers were non-adopters.

\subsubsection{Educational Status of the Respondents}

Education was therefore, expected to increase the probability of the farmers to adopt new technologies. As it indicated in the table below 22 percent of the adopters were illiterate, 33\% were read and write, 30\% attained primary education and $15 \%$ were reached senior high school, where as 54\%, 23\% and 23\% of non-adopter were illiterate, read, write and attained primary education respectively.

The data indicate that, majority of non-adopters were illiterate and low education level than adopters; these leads to the low will be the knowledge, information and resist to adopt new technologies.

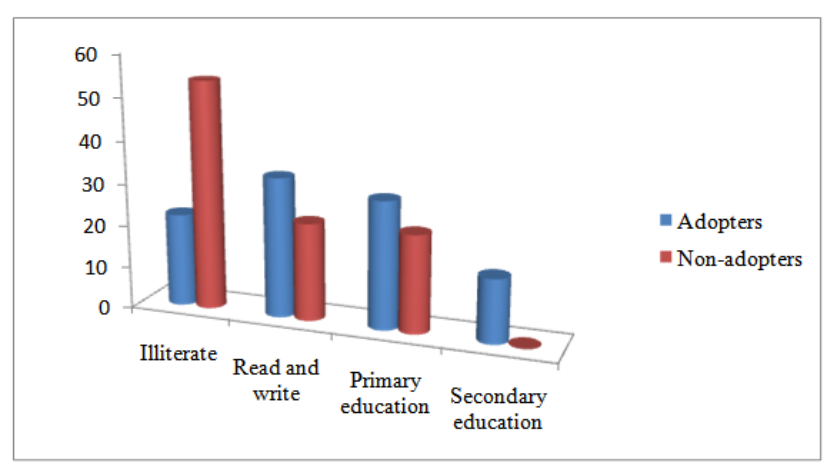

Graph 5. Educational Status to the Respondents

\subsubsection{Household Size of the Respondents}

Large households was able to provide the labor that might be required to implement improved bread wheat technologies like wheat row planting. The average household size of adopters were 6 persons and for nonadopters 4 persons. So that, adopters had larger family size (6 persons) than non-adopters.

\subsection{Socioeconomic Characteristics}

\subsubsection{Annual Income of the Respondents}

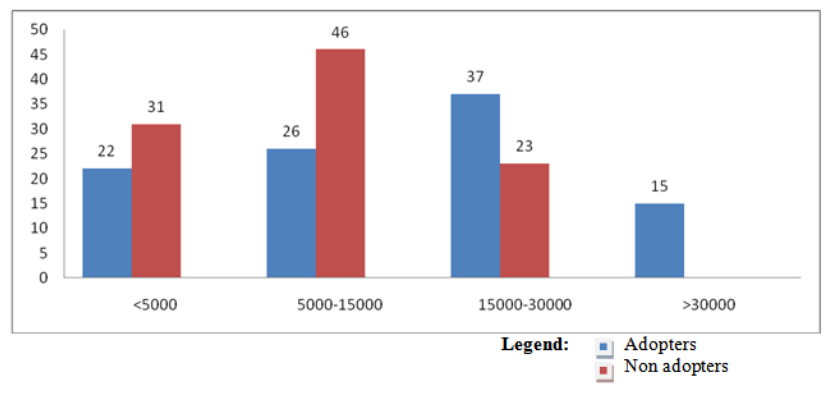

Graph 6. Annual Income of the Respondents

A person who high income has the capacity to purchase and adopt new technologies. Therefore, high level of incomes was positively influence the adoption of improved bread wheat varieties. About $22 \%$ of the adopters and $31 \%$ of non-adopters income level was less 
than 5,000 birr where as $26 \%$ of adopters and $46 \%$ of nonadopters were earn between 5000 to 15,000 birr as well as $37 \%$ of adopters and $23 \%$ of non-adopter earn between 15,000 to 30,000 birr annual income but $15 \%$ of adopters earns more than 30,000 birr annual income. From the respondents, about 90 percent of the household farms earn their income from farming activities.

\subsubsection{Farm Land}

The average farm size per house hold was 2.84 hectare of which $90 \%$ was cultivated, $4.5 \%$ was for grazing land, $1.7 \%$ was natural forest and shrubs, and $3.8 \%$ was homestead. Non-adopters possessed significantly more land (3.25 ha) than adopter (2.52 ha) in terms of total farm size and cultivated land. The average area of land allocated by adopters and non-adopters used for wheat production were 0.75 ha and 0.33 ha, respectively. Tef, wheat, maize and chickpea are the most important crops grown by the respondents in terms of area covered respectively.

\subsection{Access to Agricultural Extension Service}

Access to agricultural extension service was one of the institution characteristic hypothesized to influence farmer's decision to adopt new technologies. One can gain an extension service through various means, such as attending filed days, visiting demonstration fields, participating in formal training, listening agricultural programs on the radio and through communicating with neighbors, relatives and community leaders. Of these, the mina sources of information for the adoption of improved bread wheat varieties were extension service through development agents and district of agricultural office. Development agent were the main sources of information for the house hold farmers

As information reflected from the respondents, about $96 \%$ of adopters and $53.8 \%$ of non adopters was access to agricultural extension service. About 92.6\%, 96\% and $85 \%$ of adopter as well as $48.5 \%, 23 \%$ and $46 \%$ of nonadopters were attend filed days, formal training and participate in demonstration field, The types of contacts made by an extension agents with house hold formers were identified as individual and group extension method was $88.9 \%$ and $11 \%$ for adopters as well as $15.4 \%$ and $84.6 \%$ for non adopters, respectively

Table 1. Farmers Access to Agricultural Extension Service

\begin{tabular}{|c|c|c|c|}
\hline \multirow{2}{*}{ No } & Source of information service & Adopters & $\begin{array}{c}\text { Non } \\
\text { adopters }\end{array}$ \\
\cline { 3 - 4 } & & $\begin{array}{c}\text { Percent } \\
(\%)\end{array}$ & $\begin{array}{c}\text { Percent } \\
(\%)\end{array}$ \\
\hline 1 & Development agent & 96.3 & 53.8 \\
\hline 2 & NGOs & 51.9 & 30.8 \\
\hline 3 & Neighboring farmers & 48 & 92.3 \\
\hline 4 & Mass media & 70.4 & 46.2 \\
\hline 5 & Attended a field day & 92.6 & 48.5 \\
\hline 6 & Participated in demonstration field & 85.2 & 46.2 \\
\hline 7 & $\begin{array}{c}\text { Attended a formal training on wheat } \\
\text { production }\end{array}$ & 96.3 & 23.1 \\
\hline & $\begin{array}{c}\text { Usual types of visits made by an } \\
\text { extension agent }\end{array}$ & & \\
8 & $\begin{array}{c}\text { Individual contact } \\
\text { Group contact }\end{array}$ & 88.9 & 15.4 \\
& & 11.1 & 84.6 \\
\hline
\end{tabular}

\subsection{Access to Credit Service}

Access to credit service was hypothesized as one of the major institutional factors influencing the decision of the farmers to adopt new technologies. The farmers who access to credit have higher probability to adopt improved bread wheat varieties than those who had no access to credit service. As information obtained from the respondents, there is no credit service or down payment of improved seed or fertilizers for household adopters and non adopters from woreda agricultural office. But 18.5\% of the adopters obtained a credit service from district small micro finance. About 53\% of non adopters and 29\% of adopters obtain a credit from non formal sectors, primarily from relatives, neighbors and local money lenders. The main purpose of taking a credit service was to purchase improved seed and fertilizers. The most important credit problems identified in the study area were high interest rate, un availability of loans for agricultural input and lack of awareness. In general the study result showed that the house hold farmers were low access to credit service.

\subsection{Adoption Rate of Improved Bread Wheat Varieties}

The study was revealed that the adoption rates of improved bread wheat varieties were increased from 10\% in 2008 to $67.5 \%$ in 2013 . The rate of adoption had increased dramatically since the agricultural extension service was strongly implemented. The most cultivated improved beard wheat varieties by household adopters were 26\% Millennium, 33.3 HAR 1685 (Kubsa), 22.2\% Digelu, 11.1\% Danda'a and 7.4\% Kakeba.

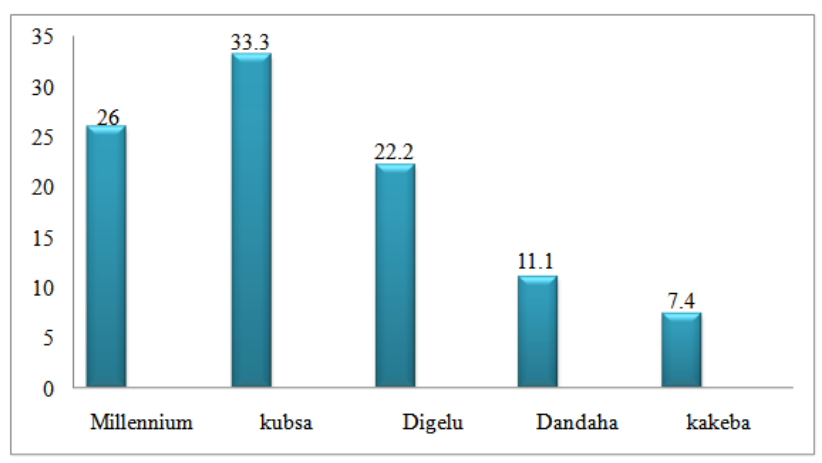

Graph 7. Varieties’ Adoption Rate

The district agricultural office (37\%), farmers to farmer's seed exchange (52\%) and NGOs (11\%) were the most important source of improved seed for the farmers in the study area. About $67.5 \%$ of the respondents were adopters and $32.5 \%$ were non-adopters. But all non adopters grow local bread wheat varieties.

The reason for adopting improved bread wheat varieties were varies, but the most important reason was that improved bread wheat varieties were more productive than local seed with better fertilizer application. In addition, 98\%, of the adopters practiced crop rotation, double cropping (23\%) and only $11 \%$ fallow their wheat land, mainly due to shortage of cultivated land.

In addition, almost all of the adopters of improved bread wheat varieties used chemical fertilizers on their wheat farm lands. DAP (di-ammonium phosphate) and 
Urea was the most common fertilizers used by both adopters and non adopters. On average the amount of DAP and UREA fertilizer used by the household adopters for wheat production were $32 \mathrm{~kg}$ and $25 \mathrm{~kg}$ per hectare respectively. This indicates that the household farmers used below the recommended rate of commercial fertilizer for wheat production. This leads to decrease the average amount of yield obtained from wheat production (1.6 ton/ha).

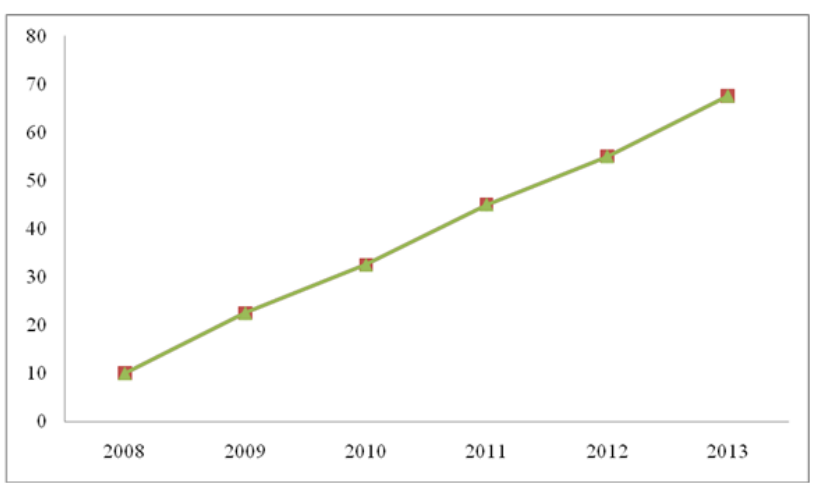

Year Start to Use Improved Bread Wheat Varieties

Graph 8. Adoption Rate of Improved Breed Wheat Varieties at Boji gabisa, Ambo District Western Shoa of Ethiopia

Many agricultural technologies have been developed and transferred to the farming community in various region of the world. Only a small proportion of farmers tend to adopt all components of these technology packages (Epoug, 1996) indicates that only $10 \%$ of farmers in Africa had adopted new technologies. It is well known that the generation and transfer of technologies is not an end in itself. The goal of increasing productivity and production of wheat will be realized if and only if the ultimate users, namely farmers adopt the technologies that were developed by research. The reason for low or no adoption of new agricultural technologies can be technical, socioeconomic and institutional. It is therefore, relevant to determined the current rate and pattern of adoption of improved wheat varieties, fertilizers and specific factors that affect their adoption.

\subsection{Constraints of Improved Bread Wheat Varieties Adoption}

There are many factors that are directly or indirectly affecting the rate of adoption of improved bread wheat varieties. According to this study, participation of farmer's on-farm demonstration, attending training course on wheat production, attending field day and farmer's access to extension service positively affect the adoption rate of improved bread wheat varieties.

High cost of improved seed, lack of income, farmers low education level, Lack of credit service, problems of availability and timely delivery of improved seed as well as insufficient quantity of delivery are the major constraints that are negatively affect the rate of adoption of improved bread wheat varieties were identified during the current study.

According to the study result, 92\% percent of the adopters and almost all of non-adopters responses indicate that the cost of improved seed was too costly and 8\% of the adopters gives response to the cost of improved seed was medium but there was no response that the cost of improved seed were cheap; the same is true for fertilizers (Table 2). So that, high cost of input does not invite household farmers for new technology adoption and it would have a negative effect on wheat production and productivity. But if the cost of improved seed may be seen in terms of affordability by small scale farmers, the house hold had high opportunity to use this technology and encourage the crops production and productivity. In addition, the availability and timely distribution of improved seed, insufficient quantity of delivery also does not satisfy the need of the respondents.

Table 2. Constraints of Improved Bread Wheat Variety Adoption

\begin{tabular}{|c|c|c|c|c|c|}
\hline \multirow{2}{*}{$\begin{array}{c}\text { S. } \\
\text { No }\end{array}$} & Constraints & \multicolumn{3}{|c|}{ Constraints in (\%) } \\
\cline { 3 - 6 } & yes & no & yes & no \\
\hline \multirow{4}{*}{1} & Cost of improved seed & & & & \\
& Cost & 92 & 18 & 100 & 0 \\
& Medium /fair & 18 & 92 & 0 & 100 \\
& Cheap & 0 & 100 & 0 & 100 \\
\hline 2 & Lack of income & 63 & 37 & 92 & 8 \\
\hline 3 & Lack of credit service & 70 & 30 & 92 & 8 \\
\hline 4 & Lack of awareness & 11 & 89 & 46 & 54 \\
\hline 5 & Problems of availability and timely & 77.8 & 22.2 & 84 & \multirow{2}{*}{16} \\
\hline 6 & delivery of improved seed & & & & \\
\hline
\end{tabular}

Waddington et al, (2009) reported that ten constraints with the greatest estimated yield losses in each crop by farming system combination. For wheat, these ten constraints likely account for 58\% of the estimated small holder wheat yield gap in Sub-Saharan Africa, with numerous "minor" constraints likely accounting for the reminder. Lack of available quality seed was reported as a primary constraint to wheat productivity in Sub Saharan Africa, affecting two third of the crop area in most years and resulting in an estimated yield loss of $167 \mathrm{~kg}$ per hectare, $8 \%$ of the total yield gap (Waddington et. al, 2009).

\section{Conclusion and Recommendation}

\subsection{Conclusion}

The adoption rate of improved beard wheat varieties were increased from $10 \%$ in 2001 to $67.5 \%$ in 2006 E.C. So, the rate of adoption had increased dramatically since the agricultural extension service was strongly implemented. Millennium, HAR1685 (Kubsa) and Digelu was the most popular improved bread wheat varieties grown by most adopters. But all non adopters grow local wheat varieties. The main reasons why non adopters did not grow improved bread wheat varieties were due to financial constraints, high cost of improved seed and lack of awareness. Almost all of the adopters of improved bread wheat varieties used chemical fertilizers for wheat production. On average, the amount of commercial fertilizer like DAP and UREA used by house hold adopters for wheat production were $32 \mathrm{~kg}$ and $25 \mathrm{~kg}$ per hectare, respectively. This indicates that, the house hold farmers used below the recommended rate of commercial fertilizers for wheat production. This lead to decrease the average amount of yield obtained from wheat production (1600 Kg per hectare) the main reason why most of the adopter doesn't use the recommended rate of commercial fertilizers was due to high cost of fertilizers. High cost of improved seed lack of income, low education level, lack 
of credit service, problems of availability and timely delivery of improved seed as well as insufficient quantity of delivery was the major constraints that are negatively affect the rate of adoption of improved bread wheat varieties were identified during the current study.

\subsection{Recommendation}

The agricultural extension service should be strengthened to promote the adoption of improved bread wheat varieties through field days, formal training and demonstration fields. The extension service should give attention in accessing information; Knowledge and skill to house hold farmers through including poor house hold farmers and women groups in its program as to participate in income generating activities. So, those who have relatively high income could increase the capacity to purchase improved seed other agricultural inputs. Accessibility of credit was found to be serious problems in the study area. Therefore, by improving the efficiency of credit system, efficient and effective delivering credit service to the farmers has to be considered as a central and core components of any development intervention. The formal credit system needs to address the credit constraints faced by small scale farmers and increase awareness about the type of credit available for agricultural production. In addition, the government should encourage farmers to form their own saving and credit cooperatives at the village level.

\section{References}

[1] Bekele H, Kotu H, Varkuijl W, Mwangi D G, Tanner (2000). Adoption of improved Wheat technologies in daba and Dodola Woredas of Bale high land, Ethiopia. Mexico D.F.: CIMMYT.

[2] CIMMYT (2000). World wheat Fact and trends. Global wheat Research in a changing world, Challenges and achievements. Mexico. D.f.: CIMMYT.

[3] CSA (2012). Report of Federal Democratic Republic of Ethiopia, Statistical Report on Socio-Economic Characteristics of the Population in Agricultural Households, Land Use, Area and Production of Crops. Addis Ababa, Ethiopia.

[4] CSA (1999). Report on Area and production of major crops. Statistical Bulletin. Addis Ababa, Ethiopia: CSA.

[5] EARO (2000). National Crop Research Strategy. Addis Ababa, Ethiopia: EARO.

[6] Epoug J, (1996). Linkage between Research and Technology users. Some issues From Africa. ISNAR Briefing paper No. 30.

[7] FAO (2005). (Food and Agriculture Organization of the United Nations). 24 Feb. 2005; Verified 14 Oct. 2005.

[8] Schulthess UB, Fiel SC, Jutzi (1997). Yield independent variation in grain Nitrogen and phosphorous Concentration among Ethiopian wheat. Agronomy Jornal. 89 (3): 497-506.

[9] Waddington SR, Li X, Dixon J, Hyman G, Vicente MC (2009). Highland temperature Mixed. 